\title{
IMPROVED LONG-TERM STABILITY OF TRANSPARENT CONDUCTING ELECTRODES BASED ON DOUBLE-LAMINATED ELECTROSPRAYED ANTIMONY TIN OXIDES AND Ag NANOWIRES
}

\begin{abstract}
We fabricated double-laminated antimony tin oxide/Ag nanowire electrodes by spin-coating and electrospraying. Compared to pure Ag nanowire electrodes and single-laminated antimony tin oxide/Ag nanowire electrodes, the double-laminated antimony tin oxide/Ag nanowire electrodes had superior transparent conducting electrode performances with sheet resistance $\sim 19.8 \Omega / \square$ and optical transmittance $\sim 81.9 \%$; this was due to uniform distribution of the connected Ag nanowires because of double lamination of the metallic Ag nanowires without Ag aggregation despite subsequent microwave heating at $250^{\circ} \mathrm{C}$. They also exhibited excellent and superior long-term chemical and thermal stabilities and adhesion to substrate because double-laminated antimony tin oxide thin films act as the protective layers between Ag nanowires, blocking Ag atoms penetration.

Keywords: Transparent conducting electrodes, Ag nanwories, Antimony tin oxides, Long-term stability
\end{abstract}

\section{Introduction}

Transparent conducting electrodes (TCEs) with low sheet resistance and high optical transmittance have attracted significant interest in recent years since they are used as an essential component in various optoelectronic applications, such as touch screen panels and solar cells [1,2]. Indium tin oxide (ITO) deposited by vacuum-based processes such as sputtering has been used as ubiquitous TCE material due to its attractive physical properties of low sheet resistance (6-090 $\Omega / \square$ ) and high optical transmittance (78-87\%) [3]. However, its drawbacks include low optical transmittance in the near-infrared region, brittleness, and the scarcity of indium resources. Moreover, to obtain high-quality ITO, a high-vacuum atmosphere $\left(<\sim 10^{-4} \mathrm{~Pa}\right)$ or high-temperature annealing $\left(>400^{\circ} \mathrm{C}\right)$ is required [3]. Therefore, because of these high-cost conditions, several new TCE materials, including metal nanowires, graphenes, and conducting polymers, have been proposed as alternatives to ITO [4]. Among these, Ag nanowires (AgNWs) offer outstanding higher sheet resistance and optical transmittance compared to ITO and their fabrication is simple via solution-based processes, such as spin-coating and spraycoating [5]. However, they have several inherent drawbacks such as poor long-term thermal and chemical stabilities, resulting in poor adhesion to substrates, which makes their practical applications difficult [6]. When the AgNWs are directly exposed to a high temperature and high humidity for a long time, they are susceptible to aggregation due to surface oxidation. In addition, the formed AgNW electrodes can easily be peeled off from the substrates by applying only light mechanical force, owing to weak adhesion between the AgNWs and substrate. These results lead to drastic increase in sheet resistance of $\mathrm{AgNW}$ electrodes [6]. In order to improve their long-term thermal and chemical stabilities, several researchers have recently proposed the use of polymer coating layers such as poly-acrylates and polyvinyl alcohol as protective layers in AgNW electrodes [7]. However, since the polymer coating layers have excessive thickness and electrical insulating property, it is difficult to obtain desired electrical and optical properties of AgNW-based TCEs. Therefore, it is necessary to develop suitable protection layers and hybrid architectures for the AgNWs.

In this study, we fabricated double-laminated ATO/AgNW electrodes by repetitive processes of spin coating and electrospraying, and investigated their electrical and optical properties as well as long-term stabilities. In addition, we chose antimony tin oxide (ATO) thin film as a protective layer for AgNWs owing to its good mechanical, thermal, and chemical stabilities, and low cost.

\section{Experimental}

Double-laminated ATO/AgNW electrodes were fabricated via spin-coating and electrospraying deposition. First, the AgNW solution was spin-coated at 2,000 rpm for $30 \mathrm{~s}$ onto

\footnotetext{
PROGRAM OF MATERIALS SCIENCE \& ENGINEERING, CONVERGENCE INSTITUTE OF BIOMEDICAL ENGINEERING AND BIOMATERIALS, SEOUL NATIONAL UNIVERSITY OF SCIENCE AND TECHNOLOGY, 232 GONGNEUNG-RO, NOWON-GU, SEOUL 139-743, KOREA

DEPARTMENT OF MATERIALS SCIENCE AND ENGINEERING, SEOUL NATIONAL UNIVERSITY OF SCIENCE AND TECHNOLOGY, 232 GONGNEUNG-RO, NOWON-GU, SEOUL 139-743, KOREA 
a glass substrate (Corning EAGLE $\mathrm{XG}^{\mathrm{TM}}$ ) to form continuous $\mathrm{AgNW}$ networks, which were baked in an oven at $80^{\circ} \mathrm{C}$ for $1 \mathrm{~h}$ to remove the residual solvent. At this time, the concentration of the AgNW solution was fixed at $5 \mathrm{mg} / \mathrm{L}$ by mixing $\mathrm{AgNW}$ ink and 2-propanol $\left[\left(\mathrm{CH}_{3}\right)_{2} \mathrm{CHOH}\right.$, Aldrich]. Then, the deposition of the ATO thin film by electrospraying was performed on the resultant AgNW networks. The ATO-sol solution for the electrospray deposition was prepared by dissolving tin(II) chloride dihydrate $\left(\mathrm{SnCl}_{2} \cdot 2 \mathrm{H}_{2} \mathrm{O}\right.$, Aldrich) and antimony(III) chloride $\left(\mathrm{SbCl}_{3}\right.$, Aldrich) into 2-propanol. The molar ratio of $\mathrm{Sn}$ to $\mathrm{Sb}$ was 10:1 for obtaining the optimized ATO thin film [8]. After stirring for $3 \mathrm{~h}$, the transparent ATO-sol solution was transferred into a syringe using a 23-gauge needle. For the electrospray, the voltage and distance between the collector and the tip of the needle were maintained at $24 \mathrm{kV}$ and $10 \mathrm{~cm}$, respectively, with the ATO solution feeding rate fixed at $0.03 \mathrm{~mL} / \mathrm{h}$. The deposition time to obtain the electrosprayed ATO thin film was $3 \mathrm{~min}$. Then, the as-prepared electrodes were baked in an oven at $150^{\circ} \mathrm{C}$ for $3 \mathrm{~h}$ and followed by microwave heating at $250^{\circ} \mathrm{C}$ for $5 \mathrm{~min}$ at heating rate of $20^{\circ} \mathrm{C} / \mathrm{min}$. The above-mentioned spin-coating and electrospraying steps were repeated twice, and the fabrication of double-laminated ATO/AgNW electrodes was completed. For comparison, pure AgNW electrodes were prepared by spin-coating, and the single-laminated ATO/AgNW electrodes were fabricated via the deposition process described above. Thus, we prepared pure AgNW, single-laminated ATO/ AgNW, and double-laminated ATO/AgNW.

The surface morphological and topological properties of the electrodes were characterized by field-emission scanning electron microscopy (FESEM, Hitachi S-4800) and atomic force microscopy (AFM, diDimensionTM 3100). The structural properties was evaluated by X-ray diffraction (XRD, Rigaku D/ Max-2500 diffractometer using $\mathrm{Cu} \mathrm{K}_{\alpha}$ radiation). The electrical and optical properties of the electrodes were measured using a Hall effect measurement system (Ecopia, HMS-3000) and via ultraviolet-visible (UV-vis) spectroscopy (Perkin-Elmer Lambda-35).

\section{Results and discussion}

Figs. 1a-c exhibit the high-magnification FESEM images of pure $\mathrm{AgNW}$, single-laminated $\mathrm{ATO} / \mathrm{AgNW}$, and doublelaminated $\mathrm{ATO} / \mathrm{AgNW}$ after microwave heating at $250^{\circ} \mathrm{C}$. In (Fig. 3a), pure AgNW appears to be composed of irregularly discontinuous nanorods and some droplet-shaped particles due to Ag migration caused by oxidation [9]. Single-laminated $\mathrm{ATO} / \mathrm{AgNW}$ and double-laminated ATO/AgNW are composed of widely distributed one-dimensional nanostructures with diameters in the range of $\sim 57.6$ to $\sim 76.5 \mathrm{~nm}$ higher than those of pure AgNW before microwave heating ( 44.5-60.7 nm, not shown here). This result indicates that the electrosprayed ATO thin film is uniformly deposited on the AgNW network. In addition, compared to single-laminated ATO/AgNW (Fig. 1b), double-laminated ATO/AgNW has an enhanced AgNW content: it can be seen that the empty region in the surface is filled by the double-laminated AgNWs (Fig. 1c). Therefore, in order to further determine the AgNW content in the electrodes, we measured the atomic ratio of $\mathrm{Ag}$ to $\mathrm{O}$ by using energy dispersive $\mathrm{X}$-ray analysis (EDX): The atomic ratios in single-laminated
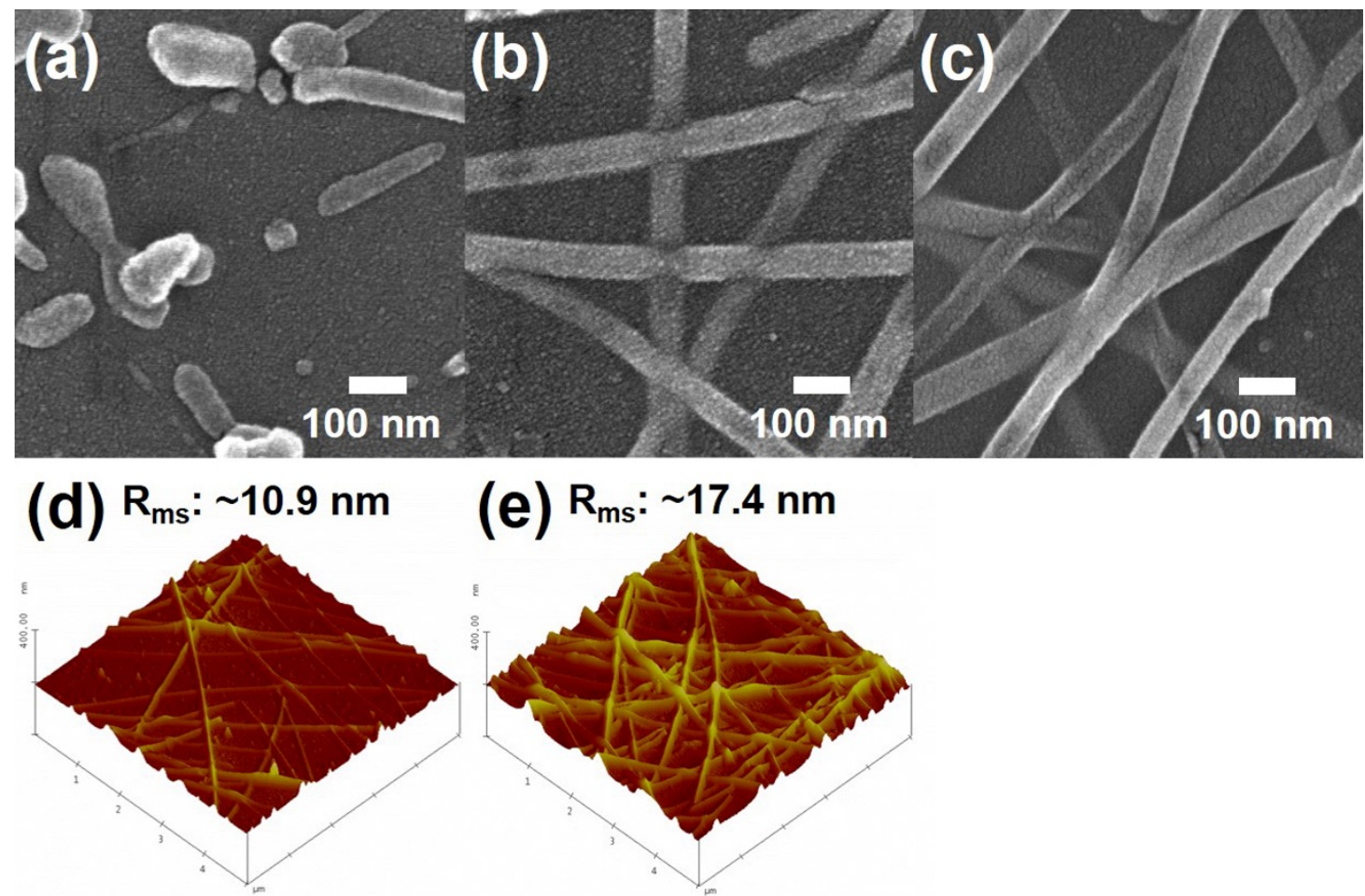

Fig. 1. High-magnification FESEM images of (a) pure AgNW, (b) single-laminated ATO/AgNW, and (c) double-laminated ATO/AgNW and AFM images of (d) single-laminated ATO/AgNW and (e) double-laminated ATO/AgNW 
ATO/AgNW and double-laminated ATO/AgNW are $\sim 22.4 \%$ and $\sim 32.5 \%$, respectively. In addition, to investigate the effect of the double lamination of $\mathrm{ATO} / \mathrm{AgNW}$ on the surface morphology of the electrodes, AFM measurements were performed. As shown in (Figs. 1d,e), double-laminated ATO/AgNW had higher root mean square roughness $\left(\mathrm{R}_{\mathrm{MS}}\right)$ that indicates standard deviation of the height in a surface, when compared to single-laminated $\mathrm{ATO} / \mathrm{AgNW}$, which is owing to their enhanced AgNW content induced by the double-lamination of AgNWs [10]. Therefore, the structure of double-laminated $\mathrm{ATO} / \mathrm{AgNW}$ can provide an effective conducting path, leading to potential improvement in electrical properties [10].

Fig. 2 shows the XRD data of all the electrodes after microwave heating at $250^{\circ} \mathrm{C}$. Their diffraction peaks are observed at $38.2^{\circ}$ and $44.4^{\circ}$, which correspond to the (111) and (200) planes, respectively, for the metallic Ag phase having a facecentred cubic structure (space group Fm3m [225]; JCPDS Card No. 87-0720). Compared to pure AgNW, single-laminated $\mathrm{ATO} / \mathrm{AgNW}$ and double-laminated $\mathrm{ATO} / \mathrm{AgNW}$ exhibit lower intensities of the peaks of metallic Ag phases, which can be attributed to the influence of the electrosprayed ATO thin film. For double-laminated ATO/AgNW, the intensities of metallic Ag phases are stronger than that for single-laminated ATO/ AgNW. This result indicates an increase in the AgNW content, which is in good agreement with the EDX results. However, no diffraction peaks for the ATO phases are observed, which implies that the electrosprayed ATO thin film has an amorphous characteristic as a result of the low microwave-heating at $250^{\circ} \mathrm{C}$ [11]. The amorphous ATO thin film is composed of three-dimensional distributed grain boundaries and disordered atomic arrangement, which results in a lower effective diffusion coefficient compared with a crystalline structure [12]. Therefore, because this structure blocks the penetration of the Ag atoms, the electrosprayed ATO thin film may act as a protective layer that improves the long-term thermal and chemical stabilities of the AgNW network [13].

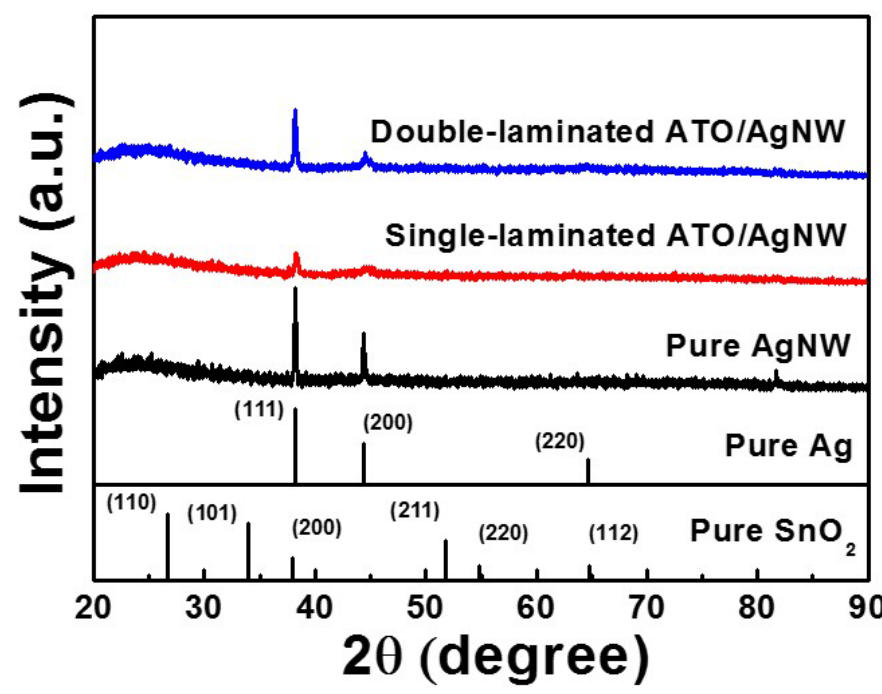

Fig. 2. XRD data of all the electrodes after microwave-heating at $250^{\circ} \mathrm{C}$

Fig. 3a shows the sheet resistance $\left(\mathrm{R}_{\mathrm{S}}\right)$ of all electrodes. The sheet resistance of pure AgNW was not measured after microwave-heating at $250^{\circ} \mathrm{C}$. In pure $\mathrm{AgNW}$, the $\mathrm{Ag}$ particles
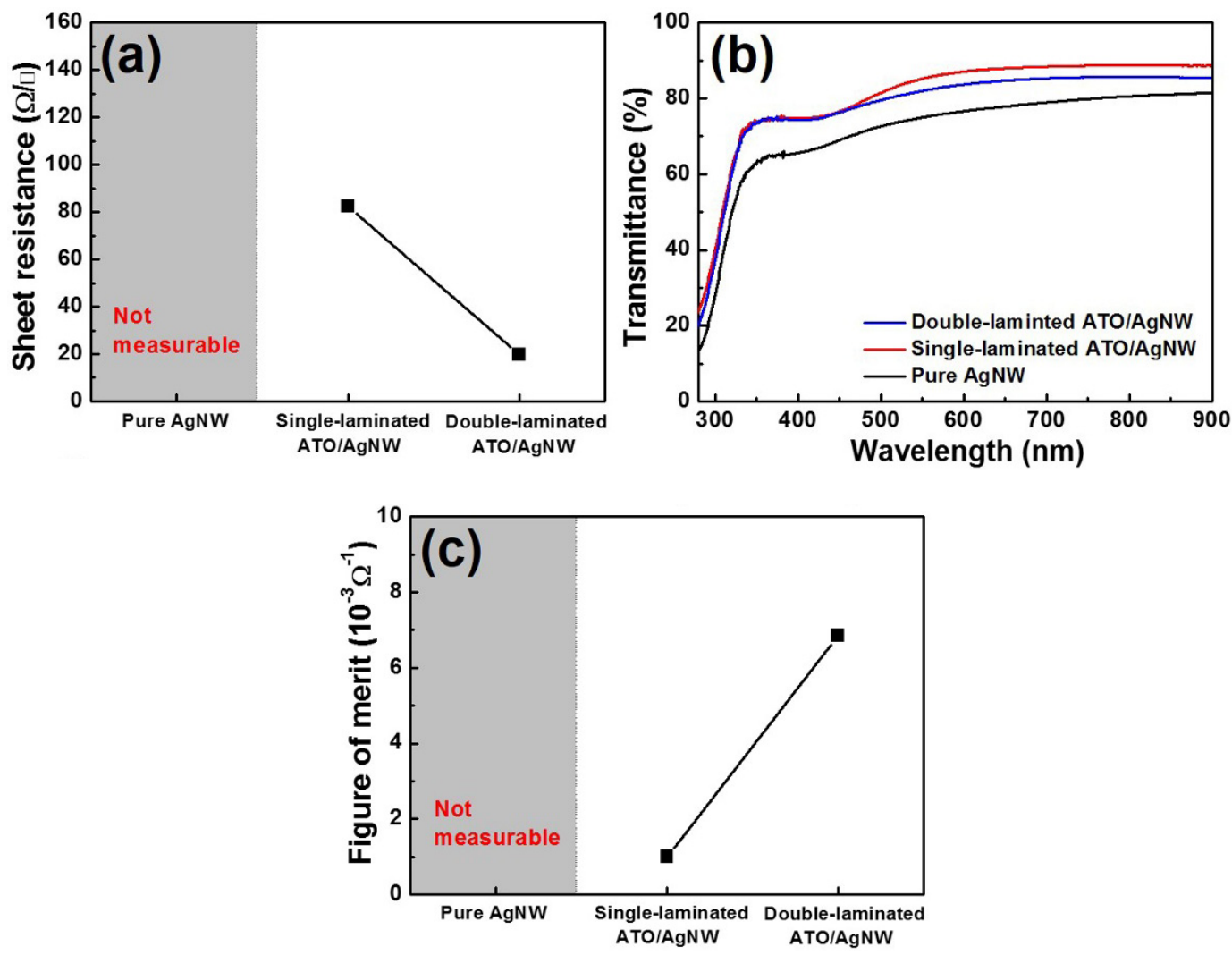

Fig. 3. (a) Sheet resistances, (b) optical transmittances, and (c) FOM values of all the electrodes 
easily aggregated due to the interruption-free movement of $\mathrm{Ag}$ atoms, as shown in (Fig. 1a). On the other hand, for singlelaminated $\mathrm{ATO} / \mathrm{AgNW}$ and double-laminated $\mathrm{ATO} / \mathrm{AgNW}$, the continuous AgNW network is retained; this is owing to the electrosprayed ATO thin films acting as the protective layer because their amorphous structure interrupts the movement of the Ag phases [13]. Therefore, the sheet resistance of singlelaminated $\mathrm{ATO} / \mathrm{AgNW}$ is measured to be $\sim 115.2 \Omega / \square$. Furthermore, double-laminated ATO/AgNW shows a significantly lower sheet resistance of $\sim 19.8 \Omega / \square$. This is because, owing to the enhanced AgNW content, double-laminated ATO/AgNW has uniform distribution of the connected metallic AgNWs, which serve as an effective conducting path [10]. Fig. $3 b$ exhibits the optical transmittances ( $\mathrm{T}$ ) of the electrodes. At a wavelength of $550 \mathrm{~nm}$, the optical transmittance was measured to be $\sim 74.9 \%$ for pure $\mathrm{AgNW}, \sim 85.1 \%$ for single-laminated $\mathrm{ATO} / \mathrm{AgNW}$, and $\sim 81.9 \%$ for double-laminated ATO/AgNW. Pure AgNW shows the lowest transmittance due to light scattering induced by irregular Ag aggregates [14]. In addition, the optical transmittance of double-laminated ATO/AgNW is lower than that of single-laminated ATO/AgNW due to the increase in the $\mathrm{AgNW}$ content. This is ascribed to the increase in light scattering in the visible region caused by the increased $\mathrm{AgNW}$ content in the electrodes, as shown in (Fig. 1) [11,14]. Based on the sheet resistance and the optical transmittance data summarized in
Table 1, we calculated the figure of merit (FOM, $\left.T^{10} / R_{\mathrm{S}}\right)$ to determine the TCE performance [14]. As shown in (Fig. 3c), while the FOM values of pure AgNW could not be calculated due to their electrical insulation, the FOM values of single-laminated ATO/AgNW and double-laminated ATO/AgNW are $\sim 1.0 \times 10^{-3}$ $\Omega^{-1}$ and $\sim 6.8 \times 10^{-3} \Omega^{-1}$, respectively. Therefore, because of its lowest sheet resistance, double-laminated ATO/AgNW is judged to possess the best TCE performance.

TABLE 1

Summary of electrical and optical properties for all the electrodes

\begin{tabular}{|c|c|c|}
\hline Electrode name & Sheet resistance $(\Omega / \square)$ & Transmittance (\%) \\
\hline Pure AgNW & - & 74.9 \\
\hline $\begin{array}{c}\text { Single-laminated } \\
\text { ATO/AgNW }\end{array}$ & 115.2 & 85.1 \\
\hline $\begin{array}{c}\text { Double-laminated } \\
\text { ATO/AgNW }\end{array}$ & 19.8 & 81.9 \\
\hline
\end{tabular}

To investigate the long-term thermal and chemical stabilities of the electrodes, we exposed the pure AgNW network (dried at $50^{\circ} \mathrm{C}$ ), single-laminated $\mathrm{ATO} / \mathrm{AgNW}$, and double-laminated ATO/AgNW to a high temperature $\left(\sim 80^{\circ} \mathrm{C}\right)$ and to high humidity ( $\sim 80 \%$ ) for four weeks, respectively. Figs. $4 \mathrm{a}, \mathrm{b}$ show the progressive change in the sheet resistance when the electrodes are exposed to $\sim 80^{\circ} \mathrm{C}$ and $\sim 80 \%$ humidity for the duration, respectively.
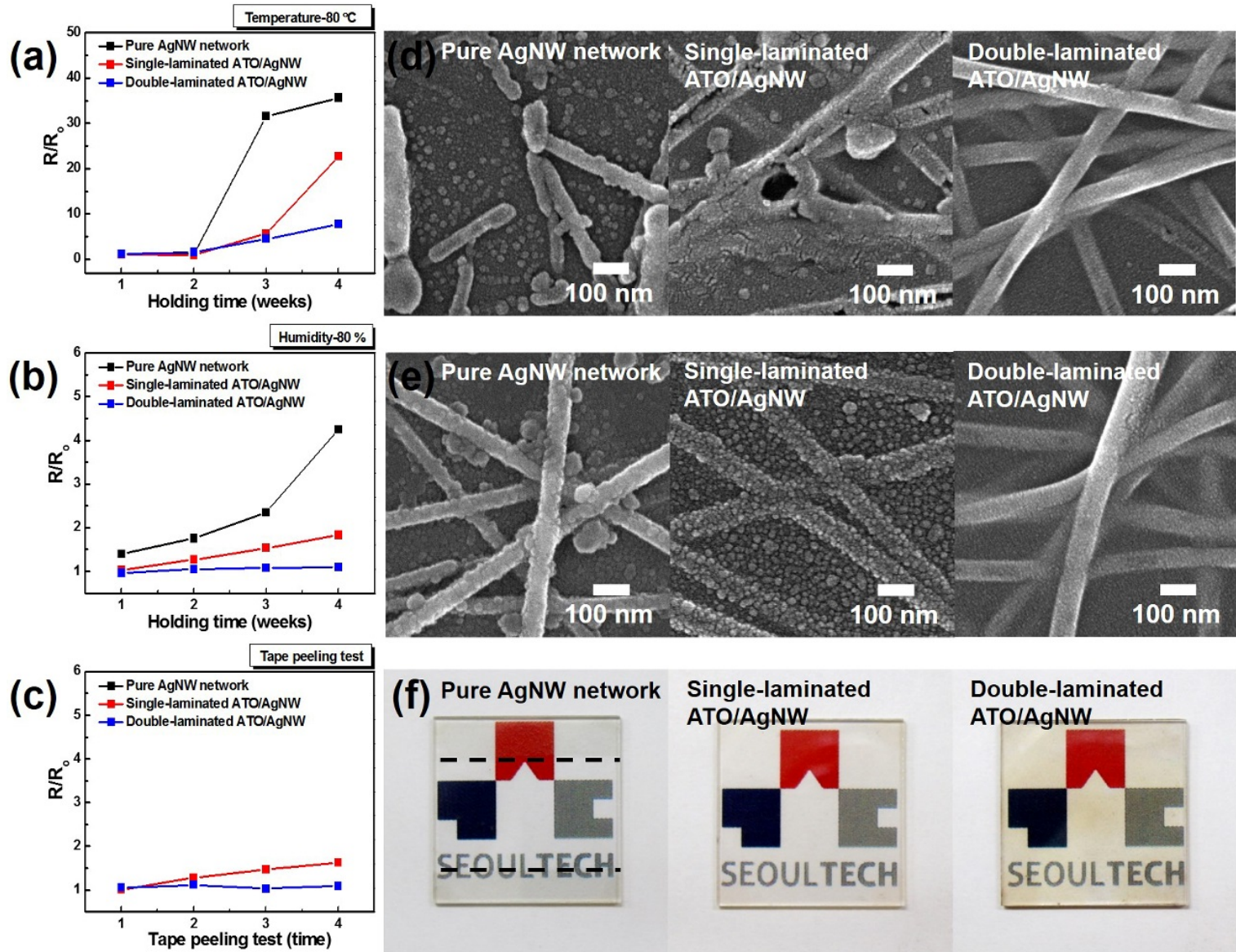

Fig. 4. Sheet resistance change of the pure AgNW networks dried at $50^{\circ} \mathrm{C}$, single-laminated ATO/AgNW, and double-laminated ATO/AgNW after exposure to (a) high thermal $\left(\sim 80^{\circ} \mathrm{C}\right)$ and (b) high humidity $(\sim 80 \%)$ for four weeks and (c) repetitive tape-peeling tests. SEM images of the electrodes after (d) thermal and (e) chemical stability tests and (f) photographs of the electrodes after the adhesion tests, respectively 
For the pure AgNW network, the sheet resistance increases by more than 35.6 times at $\sim 80^{\circ} \mathrm{C}$ and 4.2 times at $\sim 80 \%$ humidity, after four weeks. This is because the oxidation of the AgNWs is accelerated in these extreme environments. That is, when the AgNWs are oxidized, the contact junction resistance of the AgNWs increases due to morphological changes caused by the aggregation of Ag particles, as shown in the inset of (Figs. 4a,b) [8]. In addition, while the sheet resistance of single-laminated $\mathrm{ATO} / \mathrm{AgNW}$ increases by less than 23.7 times at $\sim 80^{\circ} \mathrm{C}$ and 1.9 times at $\sim 80 \%$ humidity, double-laminated $\mathrm{ATO} / \mathrm{AgNW}$ shows the least increase in sheet resistance $\left(7.8\right.$ times at $\sim 80^{\circ} \mathrm{C}$ and 1.1 times $\sim 80 \%$ humidity). As shown in the insets of (Figs. $4 a, b$ ), double-laminated ATO/AgNW shows a clear network structure without aggregation even after four weeks. This striking result indicates that double-laminated ATO/AgNW possesses excellent thermal and chemical stabilities and is superior to the others because the double-laminated ATO thin films between the AgNWs serve as protecting layers to suppress the movement of $\mathrm{Ag}$ atoms and penetration of oxygen molecules [8,13]. We also performed the adhesion test of the electrodes using the $3 \mathrm{M}$ scotch tape. Fig. $4 \mathrm{c}$ presents the changes in the sheet resistance of the electrodes after four repetitive tape-peeling tests. After the first test, the sheet resistance of the pure AgNW network could not be measured because the AgNWs are completely detached from the glass substrate by the scotch tape, as the transparency region formed on the electrode indicates in the inset of (Fig. 4c). However, for single-laminated ATO/AgNW and double-laminated $\mathrm{ATO} / \mathrm{AgNW}$, the sheet resistance changed only slightly after the four tape-peeling tests. In particular, double-laminated $\mathrm{ATO} / \mathrm{AgNW}$ is rather stable without much change in the sheet resistance despite repetitive tape-peeling tests, which indicates that the adhesion of the AgNWs to the glass substrate can be effectively improved with the double-laminated ATO thin films. In conclusion, double-laminated ATO/AgNW exhibits superb sheet resistance $(\sim 19.8 \Omega / \square)$, good optical transmittance $(\sim 81.9 \%)$, excellent thermal and chemical stabilities, and strong adhesion to the glass substrate.

\section{Conclusions}

Double-laminated ATO/AgNW was fabricated via a combination of spin-coating and electrospraying. After microwaveheating at $250^{\circ} \mathrm{C}$, whereas pure $\mathrm{AgNW}$ appeared as partially droplet-shaped particles due to Ag migration caused by oxidation, double-laminated ATO/AgNW showed widely varying nanowire morphology. In addition, compared to single-laminated ATO/AgNW ( $\mathrm{R}_{\mathrm{S}}: \sim 115.2 \Omega / \square$ and T: 74.9\%), they exhibited enhanced TCE performances $\left(\mathrm{R}_{\mathrm{S}}: \sim 19.8 \Omega / \square\right.$ and T: $\left.\sim 81.9 \%\right)$ because the double-lamination of the AgNWs results in uni- form distribution of AgNW networks because of the enhanced AgNW content. Along with the good TCE performances, doublelaminated $\mathrm{ATO} / \mathrm{AgNW}$ showed not only superior long-term chemical and thermal stabilities but also stronger adhesion to the glass substrate compared to the pure AgNW network and single-laminated ATO/AgNW. These shrinking performances are because the double-laminated ATO thin film serves as a protective layer for the AgNWs. Therefore, double-laminated ATO/ $\mathrm{AgNW}$ can be proposed as an attractive optoelectronic device TCE with both high performance and high stability.

\section{Acknowledgments}

This work was supported by the Korea Foundation for the Advancement of Science \& Creativity (KOFAC) grant funded by Ministry of Education (MOE).

This work was supported by grant No. 10046672 from the Ministry of Knowledge Economy (MKE) and R\&D Program for Technology of Specialized Materials particularly designed for venture business funded by the Ministry of Knowledge, Republic of Korea.

\section{REFERENCES}

[1] A.R. Madaria, A. Kumar, C. Zhou, Nanotechnology 22, 245201 (2011).

[2] C.G. Granqvist, Sol. Energy Mater. Sol. Cells 91, 1529 (2007).

[3] H. Han, D. Adams, J.W. Mayer, T.L. Alfold, J. Appl. Phys. 98, 083705 (2005).

[4] A. Kumar, C. Zhou, ACS Nano 4, 11 (2010).

[5] D.S. Leem, A. Edwards, M. Faist, J. Nelson, D.D.C. Bradley, J.C. de Mello, Adv. Mater. 23, 4371 (2011).

[6] J. Wang, J. Jiu, T. Sugahara, S. Nagao, M. Nogi, H. Koga, P. He, K. Suganuma, H. Uchida, ACS Appl. Mater. Interfaces 7, 23297 (2015).

[7] Z. Yu, Q. Zhang, L. Li, Q. Chen, X. Niu, J. Liu, Q. Pei, Adv. Mater. 23, 664 (2011).

[8] B.R. Koo, H.J. Ahn, Appl. Phys. Express 7, 075002 (2014).

[9] J.W. Lim, D.Y. Cho, J. Kim, S.I. Na, H.K. Kim, Sol. Energy Mater. Sol. Cells 107, 348 (2012).

[10] K.W. Seo, J.H. Lee, N.G. Cho, S.J. Kang, H.K. Kim, S.I. Na, H.W. Koo, T.W. Kim, J. Vac. Sci. Technol. A 32, 061201 (2014).

[11] K.S. Kim, S.Y. Yoon, W.J. Lee, K.H. Kim, Surf. Coat. Technol., 138, 229 (2001).

[12] O. Nakagawara, Y. Kishimoto, H. Seto, Y. Koshido, Y. Yoshino, T. Makino, Appl. Phys. Lett., 89, 091904 (2006).

[13] S. Yu, W. Zhang, L. Li, D. Xu, H. Dong, Y. Jin, Acta Mater. 61, 5429 (2013).

[14] S.-H. Cho, W.-J. Lee, Jpn. J. Appl. Phys. 49, 111102 (2010). 